\title{
A dinâmica geomorfológica das vertentes e suas implicações nas infraestruturas rodoviárias: alguns exemplos no Norte de \\ António Sousa Pedrosa* \\ Portugal
}

\begin{abstract}
RESUMO: A presença do homem e a sua ação sobre o território é um fator de grande instabilidade, pois as suas intervenções cada vez mais agressivas, possuem fortes implicações, que alteram as condições naturais de ocorrência de diversos tipos de processos morfogenéticos. Em termos naturais, no Norte de Portugal, é possível a ocorrência de diferentes tipos de movimentos em massa em vertentes com predomínio de fortes declives $\left(18^{\circ}\right.$ a $\left.3^{\circ}\right)$ cuja susceptibilidade aumenta com a coexistência de formações superficiais. Este fato agrava-se, quando o homem na sua atuação sobre o território, altera as condições naturais, implicando uma maior probabilidade de ocorrência destes mesmos processos, em vertentes onde os declives se apresentam inferiores. A construção de infraestruturas viárias ao longo das vertentes é sem margem para duvidas, uma das práticas que mais contribui para alterar a dinâmica das mesmas, contribuindo para o seu desiquilíbrio dinâmico. Efetivamente, e com base em trabalhos que temos vindo a realizar, constatamos que mesmo em locais onde estes fatores naturais são favoráveis ao aparecimento de processos de instabilidade geomorfológica é, muitas vezes, a intervenção humana que vai permitir o desencadeamento do evento, contribuindo para o aumento do risco. Assim, o objetivo deste trabalho é demonstrar que muitos dos movimentos em massa no Norte de Portugal, se encontram diretamente relacionados com a ação do homem sobre 0 território que altera profundamente o perfil das vertentes $\mathrm{e}$ introduz mudanças nas dinâmicas naturais. Pretende-se, assim, discutir neste trabalho, quais as causas e fatores que mais contribuem para o desencadear dos movimentos em massa nas vertentes no Norte de Portugal e, da importância da atuação do homem na sua ocorrência, de modo que em futuras intervenções, se evite a ruptura do equilibrio dinâmico das vertentes.
\end{abstract}

\section{The dynamics of geomorphological slopes and their implications for road infrastructure: some examples in Northern Portugal}

SUMMARY: The presence of man and his action on the territory is a major factor of instability, as their increasingly aggressive interventions have strong implications, altering the natural conditions of occurrence of various types of morphogenetic processes. In natural terms, in northern Portugal, is possible the occurrence of different types of mass movements on slopes with a predominance of steep slopes ( $18^{\circ}$ to $35^{\circ}$ ) whose susceptibility increases with the coexistence of surface formations. This fact gets worse when the man in his performance over the territory, changes the natural condition implying a higher probability of occurrence of these same processes in sections where the slopes are presented below. The construction of road infrastructure on steep slopes is with no margin for doubt, a practice that contributes most to change the dynamics of the same, contributing to its dynamic disequilibrium. Indeed, based on work we have been doing, we found that even in places where these natural factors are favorable to the emergence of geomorphological processes is, however, human intervention that will allow the triggering event, contributing to increase the risk. The objective of this paper is to prove that many of the mass movements
* Departamento de Geografia da FLUP, Centro de Estudos e Ordenamento do Território, Bolsista CAPES.

Palavras-chave: Dinâmica de
vertentes; Construção de
infraestruturas rodoviárias; Norte
de Portugal; Ação do homem;
Ordenamento do território
Key-words: City; Morphodynamics
of slopes; Road infrastructure;
Northern Portugal; The action of
man; Land planning.

Geografia Ensino \& Pesquisa, v. 16, n.1, p. 55-70, jan.jun. 2012.

Gonçalves; T. E.; Costa, M. C. L. 
in northern Portugal, are directly related to human activity on the territory that profoundly modifies the profile of the slopes and introduce changes in the natural dynamics. The aim of this work, discuss what the causes and factors that contribute to triggering of mass movements on slopes in northern Portugal, and the importance of action of man in its occurrence, so that in future interventions, to avoid the disruption of the dynamic equilibrium of the slopes.

\section{Introdução}

Os processos resultantes da evolução natural das vertentes podem levar à ocorrência de eventos de ordem geomorfológica que colocam em risco as atividades humanas. Independentemente da frequência e violência com que estes processos ocorrem a evolução das vertentes demonstra uma dinâmica não uniforme. Esta dinâmica tem períodos em que a energia utilizada para o transporte, erosão e sedimentação de materiais é extremamente baixo, enquanto que noutros momentos, a energia disponível é tão grande que permite que movimentação de grandes quantidades de materiais cuja dimensão e extensão podem ser extremamente variáveis. Estes eventos periódicos a que podemos denominar fenómenos extremos apresentam uma frequência baixa quando comparados com os processos geomorfológicos de baixa intensidade, mas de frequência elevada. Por vezes o período de recorrência é tão prolongado que faz com que as áreas susceptíveis à sua ocorrência sejam ocupadas pelo homem sem que se verifique qualquer episódio. Este fato aumenta significativamente a vulnerabilidade do território.

A presença do homem e a sua ação sobre o território é, cada vez mais um fator de instabilidade. Na verdade, essa ocupação pode ter dois aspectos distintos: i) uma ocupação do espaço sem uma interferência expressiva; ii) uma intervenção significativa com implicações que alteram as próprias condições naturais de ocorrência de processos morfogenéticos.

Assim, as condições de ocorrência de processos geomorfológicos podem ser alteradas, aceleradas e como tal, agravadas. Em termos naturais, no Norte de Portugal, é possível a ocorrência de diferentes tipos de movimentos em massa em vertentes com predomínio de fortes declives $\left(18^{\circ}\right.$ a $\left.35^{\circ}\right)$ cuja susceptibilidade aumenta com a coexistência de formações superficiais - mantos de alteração e depósitos de vertente de tipo periglaciar e/ou tardiglaciar - (A. Pedrosa, A. Pereira, 2011).

Este fato agrava-se, quando o homem na sua atuação sobre o território, altera as condições naturais, implicando uma maior probabilidade de ocorrência destes mesmos processos, em vertentes onde os declives se apresentam inferiores (A. Pedrosa, 1996; F. Rebelo, 2003).

A construção de infraestruturas, na base nas vertentes é sem margem para duvidas, uma das práticas que mais contribui para alterar a dinâmica das mesmas, contribuindo para um forte desiquilíbrio a montante da intervenção. Efetivamente, e com base em trabalhos que temos vindo a realizar, constatamos que mesmo em locais onde estes fatores naturais são favoráveis ao aparecimento de processos de instabilidade geomorfológica é, muitas vezes, a intervenção

Geografia Ensino \& Pesquisa, v. 16, n.1, p. 55-70, jan./jun. 2012

O papel do North Shopping no processo de integração metropolitana de Fortaleza e Caucaia humana que vai permitir o desencadeamento do evento, contribuindo para o aumento do risco.

Assim, o objetivo deste trabalho é demonstrar que muitos dos movimentos em massa no Norte de Portugal se encontram diretamente relacionados com a ação do homem sobre 0 território (figura 1). A urbanização, a construção de vias de comunicação e outras infraestruturas, bem como, a preparação dos terrenos para determinadas práticas agrícolas, 
especialmente em áreas de forte declive, leva a profundas alterações no perfil das vertentes, com importantes implicações nas suas morfodinâmicas. Assim, as mudanças na morfologia do terreno, na cobertura do solo e no uso da terra, estão quase sempre associados a uma alteração completa de processos hidro-geomorfológicos naturais, condicionado de uma forma indiscutível a infiltração, a escorrência superficial e o escoamento subsuperficial. Deste modo, pretende-se discutir, neste trabalho, quais as causas e fatores que mais contribuem para desencadear este tipo de processos geomorfológicos e, qual a influência que o homem pode ter, de modo que em futuras intervenções, se evite a ruptura do equilíbrio dinâmico das vertentes.

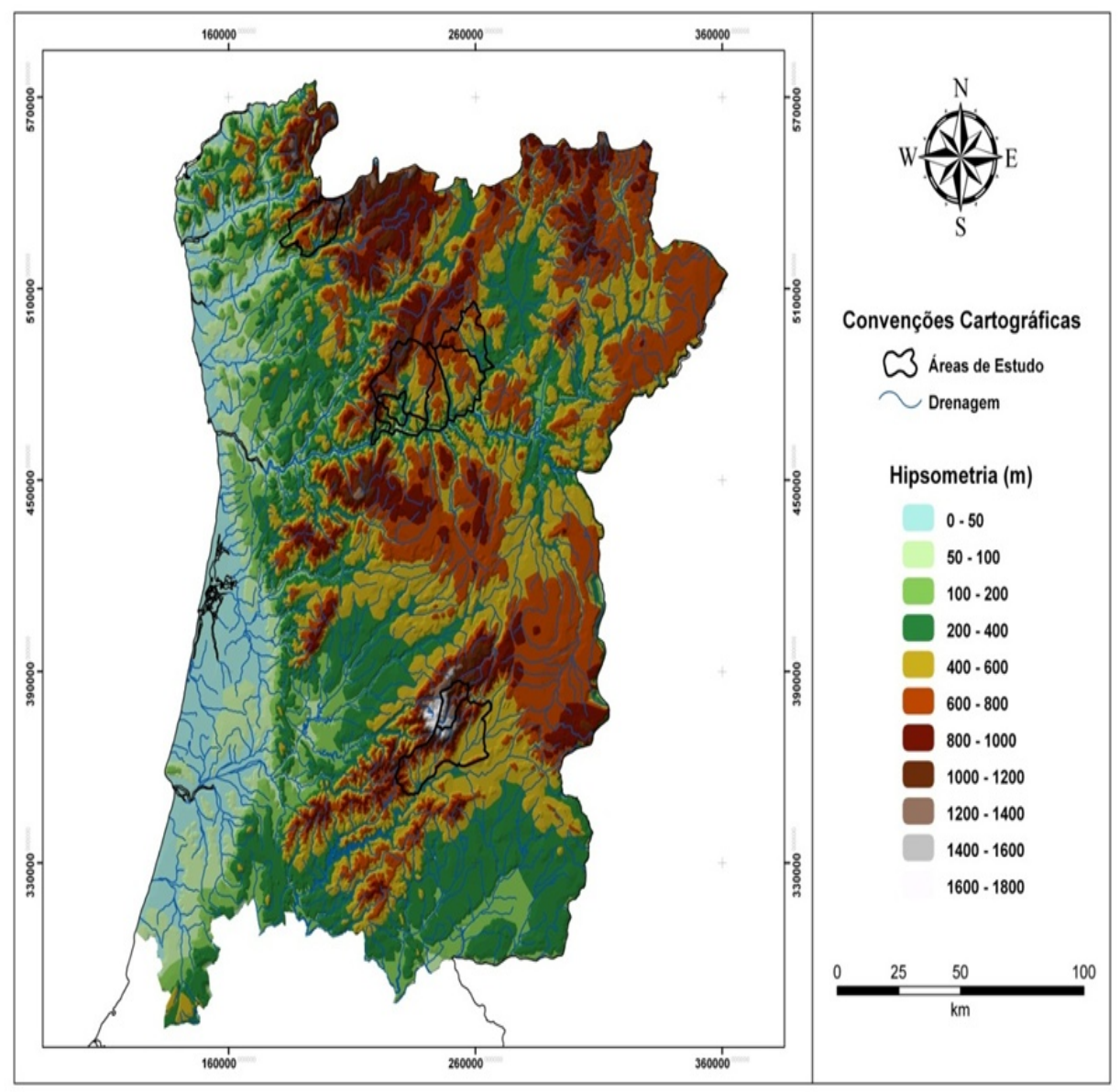

Figura 1 - Localização das áreas de estudo no Norte de Portugal

\section{O exemplo numa área de agricultura altamente especializada e mecanizada: A Região Demarcada do Douro (RDD).}

Uma das áreas de maior susceptibilidade a movimentos em massa no Norte de Portugal corresponde á RDD (A. Pedrosa, 1994; A. Pedrosa, M. Martins, 2004; A. Pedrosa et al, 2004), fato que se relaciona com a intensa atividade vitivinícola predominante na região e com 0 uso recente de técnicas de plantio extremamente agressivas em vertentes com fortes declives, muitas vezes superiores a $30^{\circ}$ (M. Martins, 2005) Outros fatores de susceptibilidade resultam da elevada percentagem de argila nos antropossolos, da inadequação dos sistemas de drenagem das águas pluviais, que não são concebidos para eventos extremos de precipitação associando-

Geografia Ensino \& Pesquisa, v. 16, n.1, p. 71-82, jan.jun. 2011

Pedrosa, A. S. 
se, muitas vezes, a falta de manutenção dos mesmos, especialmente no que diz respeito à limpeza dos tubos e canais abertos. Estas situações são agravadas pelas novas formas de plantio das vinhas, que implicam mudanças dos próprios percursos dos canais dos pequenos cursos de água, ou mesmo, à ignorância da sua existência (foto 1).

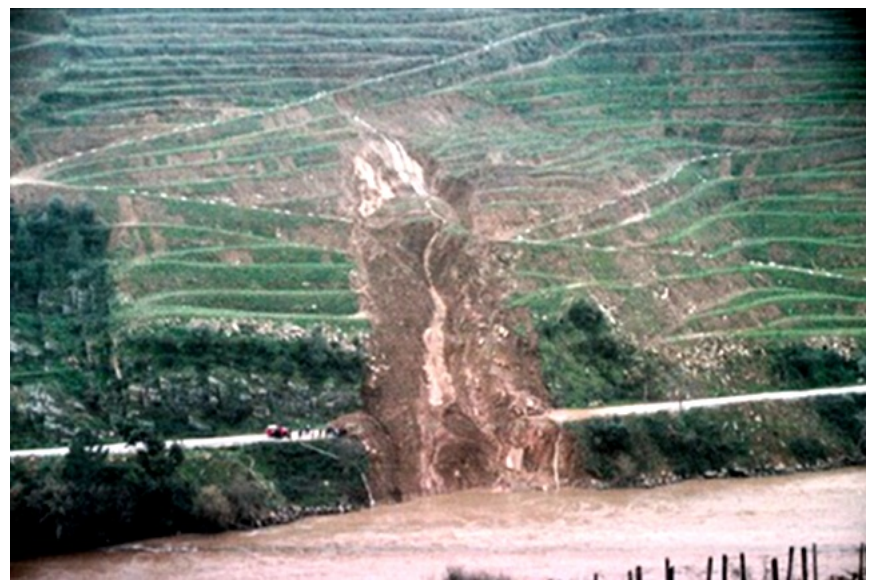

Foto 1 - Movimento em massa numa vertente de "vinha em patamares" afetando uma estrada na região da RDD.

Por outro lado a elevada ocorrência de deslizamentos em RDD relaciona-se, também, com a intensidade dos períodos de precipitação ou, então com a sua duração ao longo de vários dias, tendo como consequência a saturação dos terrenos que se caracterizam por apresentar elevadas percentagens de argila. Como consequência a água circula, acumula ou infiltra-se em locais impróprios, destruindo frequentemente terraços ou patamares vitivinícolas causando prejuízos elevados.

A ocorrência de diversos tipos de movimentos em massa acaba, também, por afetar a estrutura viária da região cujas características estão condicionadas pelos fortes declives das vertentes em que se inserem, com a estrutura fundiária da região e com a forte densidade dos valeiros, que resulta do predomínio dos xistos como substrato litológico desta região. A predominância de xistos como substrato implica um sistema de drenagem extremamente complexo, pelo que é fácil que uma estrada tenha de passar por diversas linhas de água quer sejam esporádicas, temporárias ou permanentes, de uma forma recorrente. Deste modo, o seu traçado e largura são fortemente condicionados pela dimensão e profundidade do vale, pelos declives da vertente, pelas caraterísticas perenes ou não dos cursos que terá de atravessar.

Por outro lado a construção da estrada pode influenciar o funcionamento do sistema bacia hidrográfica ou, então, a própria dinâmica do leito fluvial em si, de várias modos: i) ignorando as pequenas linhas de água, esporádicas ou temporárias, construindo apenas um pequeno aterro no leito cursos de água, para servir de apoio à rodovia, criando represas artificiais a montante; ii) utilização de canalização com tubos sub-dimensionadas dificultando a passagem do ribeiro em alturas de caudal elevado; iii) construção de sistemas de drenagem pluvial não adequados aos eventos extremos de precipitação, acontecendo frequentemente o seu transbordo e como tal a concentração de águas em locais indevidos nas vertentes aumentado a susceptibilidade aos

Geografia Ensino \& Pesquisa, v. 16, n.1, p. 55-70, jan./jun. 2012

O papel do North Shopping no processo de integração metropolitana de Fortaleza e Caucaia ravinamentos; iv) falta de limpeza de todos estes canais artificiais associados ás estradas que levam frequentemente á sua obstrução contribuindo para a circulação desordenada das águas sobre as infraestruturas e sobre as vertentes.

A construção da rede viária nesta região implica, ainda, a existência de taludes de grandes 
dimensão e barreiras com fortes declives, fatores que aumentam a suscetibilidade à ocorrência de movimentos em massa. A existência de uma elevada densidade linhas de água acarreta um forte investimento em infraestruturas de drenagem das águas superficiais, que nem sempre apresentam a adequação necessária aos eventos extremos, agravando as situações de instabilidade das vertentes com risco para a própria infraestrutura (foto 2). Associa-se, ainda, a falta de manutenção necessária nestes sistemas de drenagem artificial, particularmente no que diz respeito à desobstrução e manutenção.

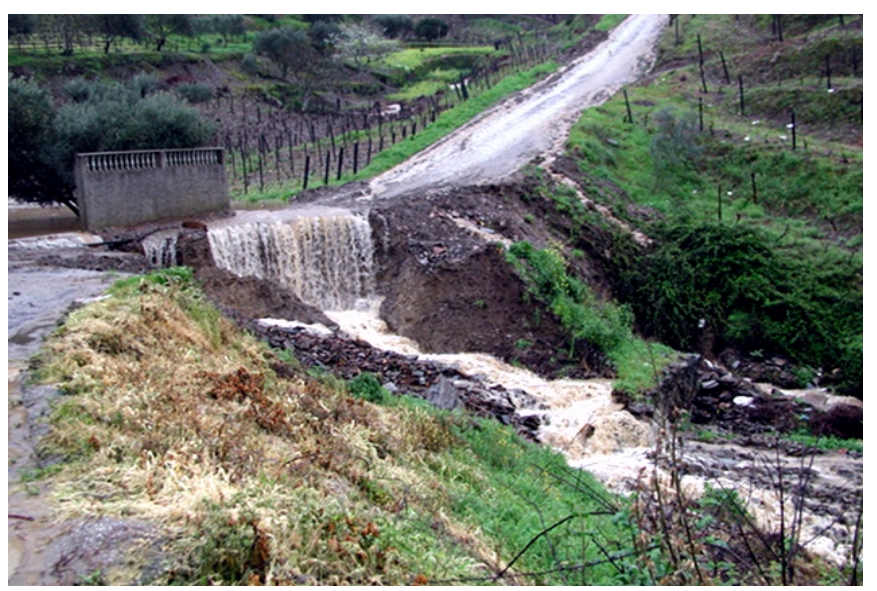

Foto 2 - Infraestrutura afetada pelo escoamento fluvial, demonstrando a sua inadequação a caudais relacionados com fenómenos extremos, na RDD.

Da conjugação das atividades agrícolas desta região que provocam uma forte da suscetibilidade do território ao desencadeamento de formas de erosão, nomeadamente movimentos em massa, com as características da rede viária que implicam um aumento vulnerabilidade do território o risco sobre as diversas infraestruturas viárias (rodoviárias e ferroviárias) é elevado resultando prejuízos consideráveis, como se demonstra a Tabela I (A. Pedrosa, J. Gonçalves, M. Martins, 2005). De fato, para além de outros impactos econômicos (como perdas de produções agrícolas e danos nas propriedades, por exemplo), o dinheiro utilizado para restaurar as estradas afetadas pelos movimentos de vertente em Janeiro de 2001 ascendeu, a cerca de 17 milhões de euros em apenas 7 municípios da RDD. A sua recuperação exigiu que o Governo Português tivesse de contribuir com cerca de $40 \%$ dos custos com dinheiro do Orçamento Geral do Estado, já que, nenhum dos municípios possuía capacidade financeira própria, para fazer a reabilitação das infraestruturas afetadas. Podemos, ainda constatar que a contribuição do Estado em alguns municípios, como Santa Marta de Penaguião e Sabrosa, atingiu percentagens superiores a $80 \%$, o que significa que os valores que tiveram de ser usados na reparação das infraestruturas, correspondiam á quase totalidade dos seus orçamentos anuais.

Devido ao seu caráter excepcional, o Inverno 2000/01 registou, nos municípios em análise, cerca de 270 deslizamentos que afetaram mais de 150 estradas incluindo várias pertencentes á rede nacional. A circulação automóvel na RDD, principalmente no Baixo Corgo, foi completamente afetada, tendo algumas povoações ficado completamente isoladas e a recuperação de algumas rodovias demorou vários meses. 


\begin{tabular}{|l|c|r|r|c|}
\hline \multicolumn{1}{|c|}{ Município } & $\begin{array}{c}\text { Número de } \\
\text { eventos }\end{array}$ & \multicolumn{1}{c|}{ Custos $(€)$} & \multicolumn{1}{c|}{$\begin{array}{c}\text { Comparticipação } \\
\text { Estatal (€) }\end{array}$} & $\begin{array}{c}\text { Comparticipação } \\
\text { Estatal (\%) }\end{array}$ \\
\hline Alijó & 18 & $638.524,20$ & $349.158,50$ & \multicolumn{1}{c|}{54,7} \\
\hline Mesão Frio & 21 & $2.026 .625,10$ & $1.246 .994,70$ & 61,5 \\
\hline Murça & 9 & $1.152 .223,10$ & $249.398,90$ & 21,6 \\
\hline Peso da Régua & 12 & $5.379 .582,90$ & $1.496 .393,70$ & 27,8 \\
\hline Sabrosa & 10 & $329.510,90$ & $299.278,70$ & 90,8 \\
\hline Santa Marta Penaguião & 11 & $2.154 .806,90$ & $1.745 .792,60$ & 81,0 \\
\hline Vila Real & 74 & $4.490 .604,30$ & $748.196,80$ & 16,7 \\
\hline TOTAL & $\mathbf{1 5 5}$ & $\mathbf{1 6 . 1 7 1 . 8 7 7 , 5 0}$ & $\mathbf{6 . 1 3 5 . 2 1 4 , 1 0}$ & $\mathbf{3 7 , 9}$ \\
\hline
\end{tabular}

Tabela I - Custos de recuperação das estradas na RDD no Inverno de 2000/01 e a comparticipação do Estado português.

\section{O exemplo de uma área de agricultura tradicional: o município de Terras de Bouro na Serra do Gerês.}

O Concelho de Terras de Bouro situado na área da serra do Gerês (Norte de Portugal) é um dos muitos exemplos que podemos mencionar onde a ocorrência de movimentos em massa também causou fortes prejuízos em infraestruturas rodoviárias. Durante o Inverno de 2001 gastou 117 473, 60 Euros só na reconstrução de estradas que foram afetadas por este tipo de processo (Foto 3).

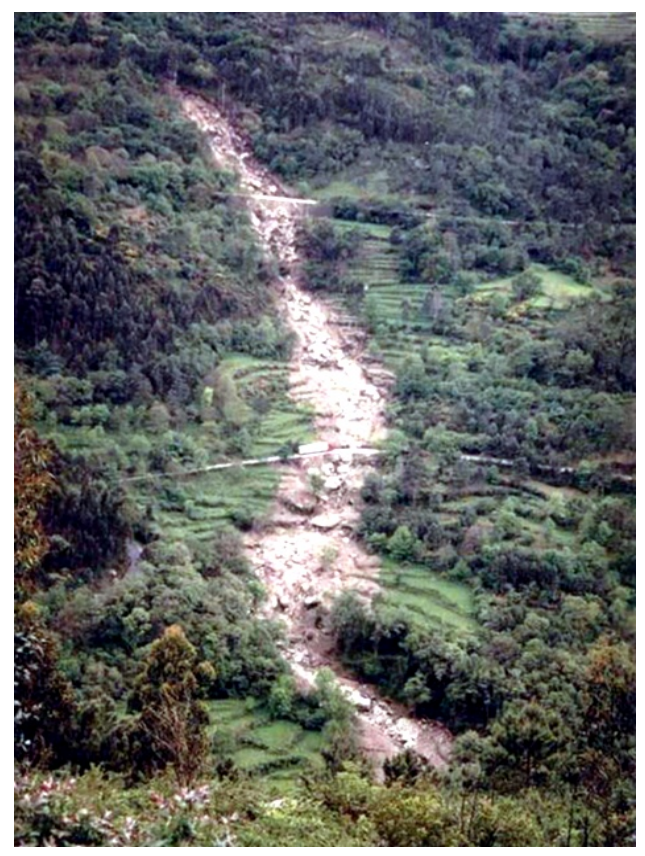

Foto 3 - Fluxo de detritos numa vertentes de agricultura tradicional, no município de Terras de Bouro, afetando duas rodovias

Geografia Ensino \& Pesquisa, v. 16, n.1, p. 55-70, jan.jun. 2012

O papel do North Shopping no processo de integração metropolitana de Fortaleza e Caucaia

Nesta área, as vertentes com declives acentuados $\left(>18^{\circ}\right)$ e voltadas aos quadrantes do norte, são favoráveis à ocorrência de deslizamentos em massa de tipo debris flow, principalmente, quando ocorre precipitação elevada e prolongada (V. Rebelo, 2007).

Outra característica que induz a ocorrência deste tipo de processos é o fato, de nas vertentes existirem mantos de alteração graníticos, relativamente profundos, que incorporam blocos de rochas graníticas de grandes dimensões, que se encontram em constante reajuste na sua dinâmica geomorfológica motivados, também, pelos declives elevados que predominam nas 
vertentes desta região, que derivam do forte encaixe dos cursos de água quase sempre associados à existência de fraturas e falhas tectónicas. A juntar a estes fatos, teremos de salientar que se pode observar a existência permanente, de fluxos superficiais e subsuperficiais de água, que resultam dos seguintes fatores: i)níveis de precipitação elevados nesta área de montanha; ii) topograficamente as partes elevadas das vertentes correspondem a áreas aplanadas cuja drenagem superficial é deficiente o que favorece a infiltração contribuindo, deste modo, para uma maior circulação interna de água que, por sua vez, facilita o desenvolvimento dos mantos de alteração em profundidade; iii) outra característica importante é, ainda, a utilização da "irrigação tradicional" que corresponde a um tipo de rega por gravidade, observado em grande número de vertentes desta área, associada a pequenos terraços agrícolas que 0 homem construiu, ao longo de tempo imemoriais e, que permite a existência de pastagens ao longo de todo 0 ano.

A irrigação por gravidade ou "rega de lima"1 contribui para o aumento de circulação de água na vertente ao longo de todo 0 ano aumentando, assim, o processo de infiltração facilitado pela própria construção dos terraços agrícolas que implicam uma redução dos declives das vertentes. É, então, mais um fator que contribuiu para a circulação interna de água e, como ocorre durante todo 0 ano, nomeadamente durante os meses de Verão, favorece as alterações químicas da rocha já que as temperaturas mais elevadas contribuem para o aumento das reações químicas.

Concluindo, os movimentos em massa que predominam nas vertentes desta área são do tipo fluxos de detritos. Explicam-se pelas características litológicas predominantes na área, pois os granitos que aqui predominam permitem a formação de mantos de alteração relativamente profundos que associados aos fortes declives (superiores a $18^{\circ}$ ) das vertentes aumentam a susceptibilidade aos movimentos em massa. Os topos aplanados que caracterizam esta área, as caraterísticas das rochas granitoides e a quantidade de precipitação anual explicam a forte infiltração e, consequentemente o desenvolviento de mantos de alteração. Esta área insere-se na denominada "Barreira de precipitação superiores a $2500 \mathrm{~mm}$ anuais (S. Daveau 1977), apresentando, também, o período seco muito pequeno, já que não ultrapassa dois meses do Verão(Julho e Agosto).Por outro lado, estas vertentes, muitas delas relacionados com a fraturarão de origem tectónica, também se encontram regularizadas por depósitos tipo tardiglaciar, característica que no Norte de Portugal é fundamental para explicar o desencadeamento de fluxos de detritos (A, Pedrosa, 2001; A. Pedrosa, A. Pereira, 2011).

De realçar, ainda, que as vertentes são ocupadas por uma agricultura tradicional baseada na construção de socalcos para obtenção de pastagens para gado - denominados tradicionalmente por lameiros - e na "rega de lima"- rega tradicional baseada na ação da gravidade - que, pelo fato, de ocorrer ao longo de todo 0 ano aumenta significativamente os índices de infiltração e, como, tal, alimenta significativamente os fluxos sub-superficiais. É mais um fator que contribui para o incremento da meteorização química do granito facilitando, deste modo, a instabilidade das vertentes onde predominam declives elevados.

Finalmente a construção de estradas processa-se nas próprias encostas das vertentes aumentando assim o grau de vulnerabilidade da área, sofrendo os efeitos da possível ocorrência dos movimentos em massa, como o caso que apresentamos na foto 3. A construção destas infraestruturas podem também induzir 0 aparecimento destes processos, principalmente quando as barreiras que resultam da sua construção apresentam dimensões elevadas $(>10 \mathrm{~m})$ e declives fortes $\left(>80^{\circ}\right)$, fatos que resultam das características de declividade das vertentes (V. Rebelo, 2007)
${ }^{1}$ Esta técnica de irrigação é um conjunto engenhoso de regadeiras de ordem hierárquica sucessivamente menor, onde 0 caudal disponível é dividido, de forma a que toda a parcela a irrigar seja coberta por uma lâmina de água que é recolhida por outra regadeira a jusante $e$, finalmente, a parte que não se infiltra, devolvida ao curso de água depois de limar toda a parcela. (Pereira, L.; Sousa, V. 2005).

Geografia Ensino \& Pesquisa, v. 16, n.1, p. 71-82 jan.jjun. 2011

Pedrosa, A.S. 


\section{O exemplo de uma vertente sem atividade agrícola: Unhais da Serra na Serra da Estrela.}

Uma característica importante nas vertentes do Norte de Portugal é a sua regularização por depósitos de vertente, relacionados com a existência períodos frios que ocorreram no passado. (A. Pedrosa, 1993; A. Cordeiro, 2004; L. Soares, 2008) A sua regularização pode possuir mais de 200 metros de extensão com espessura variável e que possuem uma forte influência nas morfodinâmicas atuais (A. Pedrosa et al, 2007; A. Pedrosa, B. Martins, 2011; A. Pedrosa, A. Pereira, 2011). Um outro atributo importante que influencia as morfodinâmicas destas vertentes são as caraterísticas heterométricas que os depósitos apresentam, que passam pelos materiais argilosos a blocos de grande dimensão, onde o grau de coesão é muito baixo (A. Pedrosa, 1993, 2001). De salientar, ainda, que em muitas destas vertentes regularizadas predominam classes de declive superiores a $25^{\circ}$, chegando a atingir valores superiores a $40^{\circ}$. A existência de formações superficiais que regularizam vertentes com fortes declives vai gerar uma forte instabilidade natural e uma susceptibilidade elevada à ocorrência de processos geomorfológicos sejam de ordem individual, sejam de movimentos em massa. Estas características acentuam a importância do fluxo sub-superficial que ocorre no contato entre os depósitos e a rocha in situ. É mais um fator essencial para explicar o incremento da instabilidade das vertentes e aumentar a susceptibilidade aos movimentos em massa.

0 exemplo que escolhemos para discutir neste trabalho relaciona-se com a construção de uma estrada entre as povoações de Unhais da Serra e Manteigas em plena Serra da Estrela. A escolha do itinerário rodoviário foi realizado muito próximo da base da vertente, tendo existido em termos técnicos a necessidade de criar barreiras com mais de $5 \mathrm{~m}$ de altura cujos declives se apresentam, na maior parte do percurso da estrada, superiores a $80^{\circ}$. Por outro lado, o fato da vertente se encontrar completamente regularizada por diversos tipos de depósitos - glaciares, periglaciares, tardiglaciares e escombreiras de gravidade ainda em atividade - e dada a espessura que os depósitos apresentam, muitas das barreiras são exclusivamente constituídas por depósitos.

Aquando da construção da estrada verificou-se de imediato o aumento da instabilidade na vertente pelo que houve a necessidade de construir uma série de infraestruturas (paredões, sistemas de drenagem), no sentido de defender a rodovia dos diversos processos geomorfológicos que se iniciaram ou se reativaram ao longo da vertente. $O$ incremento da atividade dos processos geomorfológicos na vertente em questão, relaciona-se com a espessura dos depósitos, a dimensão longitudinal das formações superficiais, o peso dos blocos que os constituem e a percentagem de argila existente, associando-se, ainda, o forte declive da vertente. Deu-se início ao aparecimento de deslizamentos, fluxos de detritos, queda de blocos, formação de ravinas que, em muitos locais, destruíram a própria estrada, assim como, as infraestruturas construídas para suporte dos materiais da vertente (foto 4) feitas aquando da construção da estrada e que se destinavam a proteger seus utentes.

Geografia Ensino \& Pesquisa, v. 16, n.1, p. 55-70 


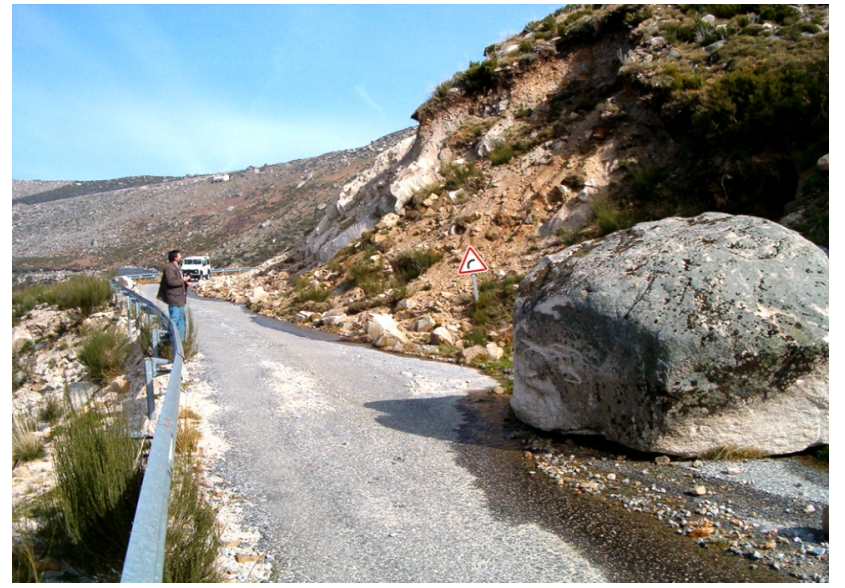

Foto 4 - Rodovia na Serra da Estrela afetada por diversos processos de evolução de vertentes que afetaram a sua estrutura. Note-se nas vertentes regularizadas por diversos tipos de formações superficiais.

Deste modo todo o investimento que foi feito na construção da rodovia foi rapidamente perdido já que esta infraestrutura teve de ser desativada dois anos após a sua construção. A escolha do seu percurso foi um erro grave, claramente relacionado pelo desconhecimento das implicações que as formações superficiais possuem na dinâmica das vertentes no Norte e Centro de Portugal. São estruturas geomorfológicas pouco coesas e muito susceptíveis á ocorrência de diversos processos morfogenéticos mesmo quando o homem não atua sobre elas (A. Pedrosa, 2001, A. Pedrosa, B. Martins, 2001, 2011). A solução do percurso teria sido a escolha da vertente oposta já que, para além de ser uma vertente soalheira apresenta apenas formações superficiais na base da vertente. Deste modo o percurso da estrada poderia ser traçado acima desses depósitos em plena rocha granítica, evitando também todos os efeitos que uma vertente sombria possui, principalmente durante os meses de Inverno, como a formação de gelo. $O$ investimento inicial poderia ser um pouco mais elevado, mas não seria certamente apenas por dois anos. Este caso é um exemplo da importância que o geomorfólogo pode ter no planeamento de infraestruturas e na sua participação em equipas multidisciplinares de ordenamento do território.

\section{Conclusão}

Muitos dos movimentos em massa no Norte de Portugal resultam da ação do homem sobre 0 território, nomeadamente devido ás atividade agrícolas, mas também, relacionados com a construção de infraestruturas viárias (A. Pedrosa, B. Marques, 1994; A. Pedrosa, L. Lourenço, J. Felgueiras, 2001; A. Pedrosa, et al., 2005). A ação antrópica pode de fato, aumentar a susceptibilidade das vertentes no que se refere à ocorrência de movimentos em massa, interagindo e reforçando as condicionantes naturais ou emergindo, mesmo, como causa direta de instabilidade da vertente.

Os exemplos que apresentamos neste trabalho reforçam de uma forma clara, esta ideia. Assim na RDD os principais fatores que influenciam a ocorrência de um elevado número de movimentos de vertente (particularmente deslizamentos de terra e fluxos de detritos) relacionam-se, por um lado, com o forte declive natural das vertentes e, por outro, com a construção de patamares vitivinícolas em vertentes de fortes declives naturais elevados (podem

Geografia Ensino \& Pesquisa, v. 16, n.1, p. $71-82$ jan.jjun. 2011

Pedrosa, A. S. 
ocorrer em vertentes com declives superiores a $40^{\circ}$ ). A existência uma rede de estradas e de caminhos muito densa para permitir 0 acesso às propriedades, aumenta claramente a vulnerabilidade destas estruturas nesta região, que se agrava ainda mais, se the associarmos as deficientes técnicas de construção e os percursos mal escolhidos. Estes fatos levam muitas vezes á existência de barreiras rodoviárias com inclinação muito elevada $\left(>80^{\circ}\right) \mathrm{e}$, a taludes com mais de $40^{\circ}$ de inclinação, constituídos por materiais pouco consolidados onde as movimentações ocorrem com facilidade e frequência, contribuindo de forma significativa para 0 aumento da susceptibilidade à ocorrência de processos geomorfológicos. Outro fator de vulnerabilidade relaciona-se com os sistemas de drenagem superficial - nas margens das estradas e na sua travessia - que se mostram extremamente deficientes e, que acabam por não permitir um escoamento eficaz quando ocorre um fenómeno extremo de precipitação.

Nas áreas de montanha de agricultura tradicional a construção de estradas em vertentes voltadas ao Norte de forte susceptibilidade à ocorrência de movimentos em massa de tipo debris flow (V. Rebelo, 2007) faz com que sejam frequentemente afetadas por este tipo de processo. De facto este tipo de vertentes apresenta uma elevada quantidade de água no solo ao longo de todo 0 ano, resultante dos fortes valores de precipitação que ocorrem nestas áreas, mas também, pela elevada infiltração motivada por condições topográficas favoráveis, como os topos extremamente planos que se verificam com frequência em áreas graníticas. Acresce ainda, como já foi referido, a transformação pelo homem dessas vertentes em áreas de "lameiros", ou seja, em pastagens permanentes, associadas á tradicional rega por gravidade que ao permitir a infiltração mesmo durante os meses de verão contribui para o desenvolvimento dos mantos de alteração e, como tal, favorece a susceptibilidade destas vertentes para a ocorrência de movimentos em massa que, acabam por afetar as estruturas que nelas são construídas.

Finalmente o exemplo da construção da estrada numa vertente regularizada por diversas formações superficiais, veio demonstrar como a construção destas infraestruturas pode desencadear toda uma série de processos nas vertentes, levando a uma forte instabilidade e a uma á rápida destruição da infraestrutura principal, assim como, de todos os suportes de vertente e dos sistemas de drenagem que haviam sido construídos.

Deste modo podemos concluir que 0 desconhecimento das dinâmicas naturais que se processam nas encostas, tem implicado um aumento substancial dos movimentos em massa no Norte de Portugal, fato que demonstra a sua relevância e a necessidade da sua inserção nas questões do ordenamento do território (A. Pedrosa, 2001). Não é demais reforçar a ideia da importância da geomorfologia para o conhecimento das morfodinâmicas territoriais e, do contributo que o geomorfólogo pode dar no planeamento de infraestruturas viárias e da sua imprescindibilidade na participação em equipas multidisciplinares de planeamento territorial.

Geografia Ensino \& Pesquisa, v. 16, n.1, p. 55-70, jan.jun. 2012

O papel do North Shopping no processo de integração metropolitana de Fortaleza e Caucaia

\section{Referências Bibliográficas}

CORDEIRO, A. R (2004) - Dinâmicas de vertentes em Montanhas Ocidentais do Portugal Central. Diss. Doutoramento, FLUC, Coimbra, 562p.

DAVEAU, Suzanne (1977) - .Répartition et Rythme des Précipitations au Portugal, Memórias do CEG, Lisboa, 192p.

MARTINS, M. (2005) - Processos de erosão acelerada na Região Demarcada do Douro, dissertação de mestrado em Gestão de Riscos Naturais, Faculdade de Letras da Universidade de Porto, Porto. 
PEDROSA, A. (1993) - Serra do Marão: Estudo de geomorfologia, Dissertação de Doutoramento, Faculdade de Letras da Universidade. do Porto, Porto.

PEDROSA, A. (1994) - As actividades humanas e os processos morfológicos. O exemplo da Serra do Marão, Territorium, Coimbra, p. 23-34.

PEDROSA, A. (1996) - A acção do Homem e a dinâmica geomorfológica no município de Amarante, Entremuros, Amarante, p. 5-9.

PEDROSA, A. (2001) - Movimentos em massa e ordenamento do território, in Actas do II Seminário sobre Recursos Naturais, Ambiente e Ordenamento do Território, Vila Real , CF711.

PEDROSA, A. et. al. (2004) - Processos de erosão acelerada na Região Demarcada do Douro: um património em risco in Actas do $2^{\circ}$ Encontro Internacional: História da vinha e do vinho no vale do Douro, Estudos Documentos 17, Porto, Instituto dos Vinhos do Douro e Porto, Universidade do Porto, Universidade de Trás-os-Montes e Alto Douro, Outubro, p. 213-235.

PEDROSA, A. et al. (2005) - Mass Movements in North of Portugal and its consequences in transports and communication systems, poster apresentado in International Conference on Landslide Management, Vancouver (Canadá),1p. Office/Default.aspx?Module=Files/FileDetails\&ID=2540.

http://www.pluridoc.com/Site/Front

PEDROSA, A. et al. (2007) - Quaternary evolution of the Serra do Marão and its consequences in the present dynamics, Territorium, Revista da Associação Portuguesa de Riscos, Prevenção e Segurança, n¹4, p. 33-43.

http://www.pluridoc.com/Site/FrontOffice/default.aspx? module=Files/FileDescription\&ID=2539\&state=SH

PEDROSA, A.; GONÇALVES, J.; MARTINS, M. (2005) - Land management and landsildes in North of Portugal, comunicação apresentada in International Symposium on Geography, Junho, Antalya, Turquia. 35p. http://www.pluridoc.com/Site/FrontOffice/default.aspx?module=Files/ FileDescription\&ID=6747\&state=TDR.

PEDROSA, A. LOURENÇO, L.? FELGUEIRAS, J. (2001) - Movimentos em massa: exemplos ocorridos no Norte de Portugal, Revista Técnica e Formativa da Escola Nacional de Bombeiros, Ano 5, nº 17, p. 25-39

PEDROSA, A. MARQUES, B. Serpa (1994) - Man's action and slope erosion: A case study in Tâmega Basin (1981), Territorium, 1, Coimbra, p. 23-34.

PEDROSA, A.? MARTINS B. (2001) Os movimentos em massa e os depósitos de vertente em áreas metassedimentares: alguns exemplos no Norte de Portugal in Actas do II Seminário sobre Recursos Naturais, Ambiente e Ordenamento do Território, Vila Real, C0161169.

PEDROSA, A.; MARTINS, B. (2011) - As formações superficiais no Norte de Portugal e suas implicações nos processos erosivos actuais. Geografia. Ensino \& Pesquisa (UFSM). , v.15, p. $55-72$.

PEDROSA, A. MARTINS, M. (2004) - Precipitações extremas na região Demarcada do Douro in Actas do $2^{\circ}$ Encontro Internacional: História da vinha e do vinho no vale do Douro, Estudos Documentos 17, Porto, Instituto dos Vinhos do Douro e Porto, Univ. do Porto, Universidade de Trás-os-Montes e Alto Douro, Outubro, p. 195-212.

PEDROSA, A.; PEREIRA, A. (2011) - A integração das formações superficiais na modelação e cartografia do risco geomorfológico: o caso da Serra do Marão, Soc.\& Nat, Uberlândia, ano 23, nº 3, p. 529-544.

REBELO, F. (2003) - Riscos Naturais e Acção Antrópica. Estudos e Reflexões. Coimbra, Imprensa da Universidade, 286 p. $2^{\mathrm{a}}$ edição,

REBELO, V. (2007) - A importância do Estudo dos Riscos Geomorfológicos no Ordenamento do concelho de Vieira do Minho, dissertação de mestrado em Gestão de Riscos Naturais, Faculdade de Letras da Universidade de Porto, Porto.

SOARES, L. (2008) - A influência das formações superficiais no âmbito dos processos de erosão hídrica e movimentos de vertente no NW de Portugal, Porto, Dissertação de Doutoramento em Geografia Física apresentada na Faculdade de Letras da Universidade do Porto, 850p.

Geografia Ensino \& Pesquisa, v. 16, n.1, p. 71-82 jan.jjun. 2011

Pedrosa, A.S. 


\section{Correspondência}

António de Souza Pedrosa -

E-mail: aspedros@gmail.com

Recebido em 10 de maio de 2012

Aprovado em 12 de junho de 2012.

Geografia Ensino \& Pesquisa, v. 16, n.1, p. 55-70,

O papel do North Shopping no processo de integração metropolitana de Fortaleza e Caucaia 